RESEARCH ARTICLE

\title{
Developing Meaningful and Practical Global Experiences Through Student-Faculty-Community Partnerships
}

\author{
*Carmen Monico, Department of Social Work and Sociology, North Carolina Agricultural and \\ Technical State University, USA
}

Ketevan Kupatadze, Department of World Languages and Cultures, Elon University, USA

Contact: ccmonico@ncat.edu

\section{ABSTRACT}

The student co-teacher and co-mentor model introduced in this article seeks to promote learning, reflection, and critical thinking and to nurture students' intellectual curiosity through high academic standards and experiential learning, including community engagement and study abroad. Similarly, scholarship of teaching and learning research on pedagogical partnerships demonstrates improved learning, selfawareness, and engagement with the educational material as a result of students' partnership and collaboration with faculty and staff. Limited existing research combines the student-faculty partnership model with the development of students' intercultural competencies in experiential learning contexts, such as practicums, internships, and study abroad. This article focuses on approaches to engaging Elon University students as partners in a practicum course in Guatemala. The study provides evidence of the model fitness as well as the potential for replication of higher education approaches, such as the emerging global learning model for practicum instruction.

\section{KEYWORDS}

student as partners, global engagement, student-directed research, service learning, human services

SHIFTING THE FOCUS FROM FACULTY TO STUDENTS AND FROM TEACHING TO LEARNING: A TEACHING AND LEARNING PHILOSOPHY ENABLING STUDENTS AS PARTNERS

Students as Partners (SaP) in teaching and learning in higher education, or simply Students as Partners, is a pedagogical approach that has been embraced relatively recently by many higher education institutions, primarily in the United States, the United Kingdom, Canada, 
and Australia. SaP implies students and faculty working in collaboration as partners to improve teaching and learning experiences (Mercer-Mapstone et al., 2017). Healey, Flint, and Harrington (2014) describe SaP as "a relationship in which all involved-students, academics, professional services staff, senior managers, students' unions, and so on-are actively engaged in and stand to gain from the process of learning and working together" (p. 12). They highlight the following values underpinning the practice: authenticity, inclusivity, reciprocity, empowerment, trust, challenge, community, and responsibility.

In the traditional hierarchical relationship between faculty and students, faculty assume the role of experts who take on the responsibility of sharing their expertise with students. Contrary to this common approach, SaP views teaching as an opportunity for partnership, a more egalitarian and equitable experience closely aligned with Freire's pedagogical philosophy. According to Freire (1968), the banking model of education, one that is understood as a business transaction between the universities and the students as clients, is not conducive to self-learning and even undermines the healthy development of students. Additionally, it can further social oppression by reinforcing the unequal relationship between the instructor and students, wherein the instructor becomes the central or only authority and knower (Freire, 1968). In that context, constructivism can serve as an alternative paradigm using hermeneutic dialogue (Guba \& Lincoln, 1989) that builds on students' prior and tacit knowledge, assisting students in the process of developing greater sophistication of that knowledge, instead of "depositing" knowledge into the learner's head. Similarly, a partnership-based model of education is a "reciprocal process through which all participants have the opportunity to contribute equally, although not necessarily in the same way, to curricular or pedagogical conceptualization, decision-making, implementation, investigation, or analysis" (Cook-Sather, Bovill, \& Felten, 2014, pp. 6-7).

Hence, the implementation of collaborative and partnership-based projects as we practice teaching and learning has the potential to develop more equitable relationships within academia. It can model such relationships for the communities outside of its limits to educate more active, engaged, and motivated students with a heightened self-awareness, a more conscientious mindset, and a stronger sense of responsibility. It can create an inclusive environment both within universities and communities, an environment in which individuals feel they belong and where trusting and respectful relationships are cultivated.

This article focuses on a service-learning course titled "The Practicum Away to Guatemala" that adopted some of the principles of student-faculty partnership pedagogy in order to improve students' and all other participants' teaching and learning experiences, as well as to develop a better sense of trust, belonging, and community building. Here is the list of the types of partnership-based elements used through the course:

- Instructor as facilitator who models active and engaged learning;

- Self-directed learning, with the use of assignments prior to departure in which students identify their goals and objectives;

- Students as co-leaders and co-researchers, including:

- Student-led classes;

○ Students designing, implementing and evaluating assignments;

- Student-directed research projects; 
- Students self-monitoring their progress;

- Students, instructors and partners constantly reflecting on and evaluating the process of teaching and learning;

- Students self-selecting their placement or the agency they were going to work with;

- "Buddy" (friendship) system among students to construct shared experiences; and

- Developing skills and knowledge to treat differences (such as social class, race, ethnicity, nationality, gender and sexual orientation, etc.) with respect and honesty.

\section{DISCIPLINARY CONTEXT AND METHODOLOGY}

The Practicum Away to Guatemala (HSS 382) was designed to engage Elon students majoring or minoring in Human Service Studies (HSS) and Public Health Studies (PHS) in professional work at human-service organizations in Antigua, Guatemala over the winter term for 3 weeks. Students have an immersion experience and are exposed to Mayan people in the Western Highlands and the Garifuna culture on the Atlantic coast. Students participate in ecotourism and traditional ethnic ceremonies, learning appreciation for other cultures. In winter 2014, a multi-year study was designed to learn from the students' lived experience and draw implications for theory, practice, education, and research. Figure 1 offers a concise description of the context, purpose, methodology and partnership-based instruction employed when developing and delivering the Practicum Away to Guatemala. We follow with a detailed description of each of these elements. 


\section{Figure 1. Diagram of context and methodology}

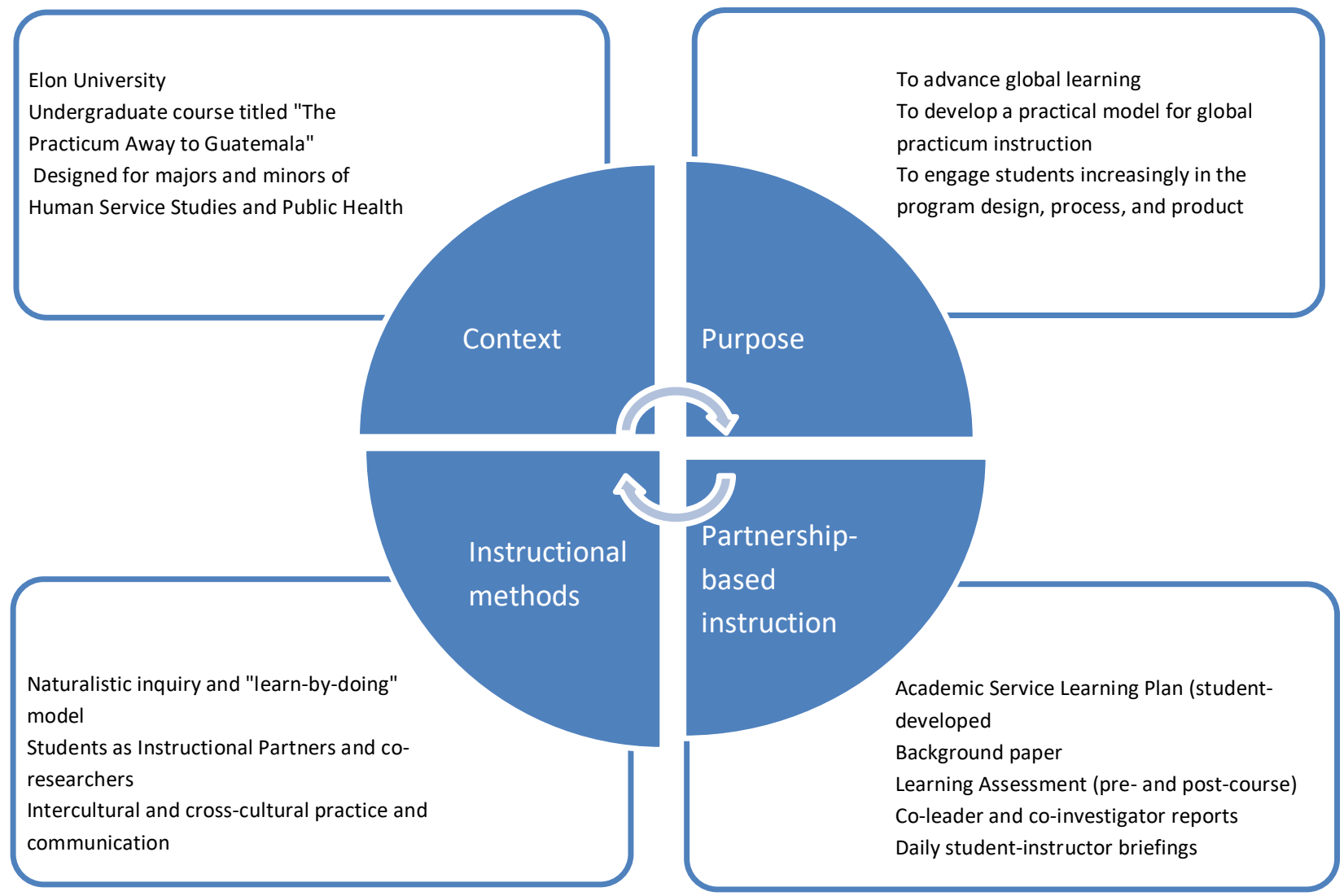

The course was developed in collaboration with international and local partner organizations to advance global learning and to develop a practice model for global practicum instruction. A "naturalistic" inquiry was adopted to draw lessons from the experiential learning of students engaged in professional practice in Guatemala. Naturalistic inquiry "is done in the field so data can be observed in its natural context and evaluated in terms of its connection with its social environment . . . with the result that theory is created from the data observed" (Harper \& Lantz, 1996, p. 7). This qualitative research involved the development of three phases in the inquiry. The first phase, the orientation and overview of the inquiry, included the formulation of a research question and working hypotheses (Guba \& Lincoln, 1989; Lincoln \& Guba, 1985; Rodwell, 1998). The other two phases of the constructivist inquiry involved the inquiry process and inquiry product (Guba \& Lincoln, 1989; Lincoln \& Guba, 1985; Rodwell, 1998).

Students have played an important role in improving the program design from year to year, with some of them assuming roles as co-leaders of the program and co-investigators in the inquiry process and the inquiry product. Culturally competent human services have been studied with little attention to context and outcomes. The Guatemala practicum sought to enhance students' intercultural competencies through their systematic reflections on the knowledge and skills acquired, as well as in their own attitude changes students observed. During the preparatory course and while engaged in field practice, students were introduced to the Association of American Colleges and Universities (AAC\&U) Intercultural Knowledge and 
Competence Value Rubric (n.d.), cross-cultural practice in Harper and Lantz (1996), and generalist, strength-based, problem-solving practices in Timberlake, Zajicek-Farber, and Sabatino (2008). Students "learned by doing" through their professional practice with diverse people in different settings, either in interacting with indigenous groups and low-income families in the Highlands or with Afro-Latino communities on the Atlantic coast. They engaged with Guatemalan organizations serving mostly socially excluded populations and vulnerable populations, such as malnourished children, survivors of domestic violence, and people with severe physical and intellectual disabilities.

Intercultural sensitivity was a model used for students to self-assess their cultural competence through course development (Bennett, 1993). This model promotes the recognition of how those exposed to other cultures are able to move from ethnocentrism to ethnorelativism through the development of various stages of experience of cultural difference, that is, from denial of the others' culture, to defense of one's culture, to minimization of the others' culture, into acceptance of and finally adaptation to the new culture, and integration into a more ethnorelative stage (Bennett, 1993). Students were encouraged to use this theoretical framework to examine systematically their direct practice and place themselves on the intercultural sensitivity continuum. Students were also encouraged to apply in their daily practicum activities the biopsychosocial model of Borrell-Carrio, Suchman, and Epstein (2004), the integrated-perspective approach of Cox and Pawar (2013), the ethical decision-making model of Kenyon (1999), and the multiple identities approach of Robinson-Wood (2013).

Course participants included three males and 33 females, all undergraduate students at Elon University either majoring or minoring in human service studies with some students also concentrating on public health studies. Two student-researchers serving as co-leaders and coinvestigators are included in this total number of practicum participants; they were later engaged in undergraduate courses of one to four credits prior, during, and after the winter term practicum. They were supported through both university grants and scholarships to compensate for their work in formal roles as program assistants. During the preparatory courses, students in the Guatemala practicum were invited to participate voluntarily in the associated study. If they agreed, students were asked to sign Internal Review Board (IRB) consent forms prior to departure to Guatemala.

Through the daily seminars and weekly journals, students engaged in verbal and written reflections that allowed them to think critically about their practice in light of the theories they had learned or were reading as they were engaged in practice. Faculty co-led daily seminars with student leaders and took field notes of the discussions held and of their observations from the field work of other students. The Integrative Process Model (IPM) Paper enabled students to reflect upon their field experiences through a careful and systematic analysis of the dissonance created when engaging with those different from them (Kiser, 2000). The Student Evaluation of Practicum Field Experience and the Supervisor Evaluation also comprised the data that were later analyzed to assess the student's process in becoming culturally competent. Other assignments from which data were obtained included a background paper submitted prior to departure, the students' Academic Service-Learning Plan in which they self-defined goals and objectives for their practicum experience, and the learning assessments, completed by students before departure and after completing the practicum experience. In addition, 
reports from the two student partners who also served as program assistants and researchers have been used to prepare this article. Besides assignments, additional sources of information used to conduct this IRB-approved research project included student-faculty daily debriefings on the discussion of readings; faculty interviews of directors, service delivery staff, and clients of community partners in Guatemala; and faculty records, such as notes from debriefing meetings and field trips and observations from field supervision visits.

Data analysis included the identification of key themes drawn from the literature review and a thematic analysis of data collected over the course of five years. Emerging themes relevant to SaP are presented in the Findings and Discussion section. A student leader analyzed the student evaluations of the practicum field-experience forms and connected the findings to the emerging global learning model for practicum instruction explained in the next section. Much more analysis is yet to be done from the data collected, particularly that supporting the model for practicum instruction; however, that evidence is beyond the scope of this article.

As indicated earlier, multiple sources of data collection were used throughout the practicum; however, the findings and discussion that follow are inferred from selective documentation and are most relevant to the application of and reflection on the SaP approaches.

\section{FINDINGS AND DISCUSSION}

The Guatemala practicum is a course taking place across languages (English, Spanish, and Mayan languages), cultures (American and Guatemalan; bi-cultural and multicultural in some cases), power dynamics (different races, ethnicities, gender identities, and sexual orientations), and positions (faculty, student, student leader, group leader, community partners and members). As discussed above, these multiple contexts, dynamics, and roles presented numerous opportunities and challenges for faculty and students, as well as community partners and members. Opportunities for strengthening relationships within each group, for maximizing student engagement and leadership, and for making a lasting impact in the community were created as part of the program. Thus, planning and close coordination with community partners was an essential program component, in addition to the prolonged engaged, strong partnerships and knowledge of the country that the faculty already had prior to the experience abroad.

Like in any other study-abroad program, both anticipated and unexpected challenges emerged, for instance, the possible burnout from the intense experience abroad and from serving a community different from the student population. Also, the ethnicity of the faculty was different (Salvadoran American), and the student population was mixed (most identified as White but several were Black and Latinx, in addition to being from various queer identities). This is why a combination of cultural and recreational activities, in addition to the professional practice in hospitals and other social service settings, became crucial. Those activities, plus the "buddy" system, were instrumental in creating the bonding necessary for supporting each other during stressful times, such as engaging in non-verbal communication, handling unexpected or unplanned circumstances, and learning to navigate a very different culture. Student leaders, who had been in Guatemala before, supported the cultural immersion of the other students 
and helped as mediators in the communication between faculty and other students while the faculty focused on facilitating coordination with community partners.

Managing such a complex program became a growth opportunity for both faculty and students, as every challenge was addressed as such and not as an impossible or unsolvable situation. Daily coordination meetings between faculty and student leaders, the evening reflection sessions between them and other students, and the constant coordination with community partners are what made it possible to address tensions as they flared, to troubleshoot, and to problem solve. As discussed in greater detail next, setting a tentative plan and assuming iterative and collaborative approaches were more helpful than setting rigid goals and objectives for engaging students as partners in the Guatemala practicum courses developed.

\section{Participants' perceptions about global learning when adopting partnership-based pedagogy in an inter-institutional and cross-cultural setting}

The literature suggests that there is a need for more systematic research regarding discrete inter-institutional and cross-disciplinary initiatives to illuminate "how partnerships translate across disciplines, institutions, countries, and cultures" (Mercer-Mapstone et al., 2017, p. 18), as well as regarding the experiences of faculty and students identified or selfidentifying as minorities (Kupatadze, 2019). The program described in this article is an attempt to capture the teaching and learning experience of a study abroad program that seeks to help students advance global learning while developing professional skills in the delivery of services in an international setting. Among the different models of SaP, this particular program used students as co-designers of a teaching and learning model, engaging them as partners in the design and development of course content, assessment tools, and instructional materials, among other aspects.

\section{Using the "ladder of active student engagement in teaching and learning"}

In this article, we make use of the ladder of student participation as we describe the types of student involvement in the process of the design and implementation of a specific curriculum. We identify students, faculty, and community as partners because of the active role all of them play at various points in the design of the course that combines the study abroad with the service-learning experience. The partnership extends to the development of the course content (where students act as co-designers of instructional materials), the assessment of teaching and learning throughout the duration of the course (where students act as consultants offering consistent feedback on the course), and the engagement of students as coresearchers in the scholarship of teaching and learning (SoTL).

The development of partnership-based pedagogical cultures in higher education institutions in the United States and abroad has confronted many challenges, such as frequent time constraints, institutional pressures, and resistance from students, among others; as a result, these approaches have assumed a more passive role. Bovill (2017) proposes partnership as one of many types of student participation. To describe the wide spectrum of opportunities and ways to involve students as co-designers of pedagogical tools and practices, Bovill and Bulley (2011) developed a "ladder of student participation in curriculum design" (p. 5). The 
ladder (see Figure 2) recognizes that the SaP approach requires a very high level of participation from students and allows for the constraints that faculty as well as students realistically face when engaging in partnership. The ladder clearly shows that the level of student engagement and participation in the process of the design of the curriculum can and should be adjusted based on the needs and capabilities of the students, the needs of the course material, and the goals and limitations of the faculty. If these and other factors are not taken into consideration, "we run the risk of enacting partnerships that do not feel like partnerships to those involved, with the resultant danger of alienating some students and academic staff in the longer term" (Bovill, 2017, p. 2). Bovill (2017) concludes that

acknowledging that contexts are different helps us to adopt appropriate SaP approaches in particular settings. This is about recognizing the huge range of ways in which different students can engage as partners in different aspects of learning and teaching at different times. (p. 2) 
Figure 2. Ladder of student participation in curriculum design*

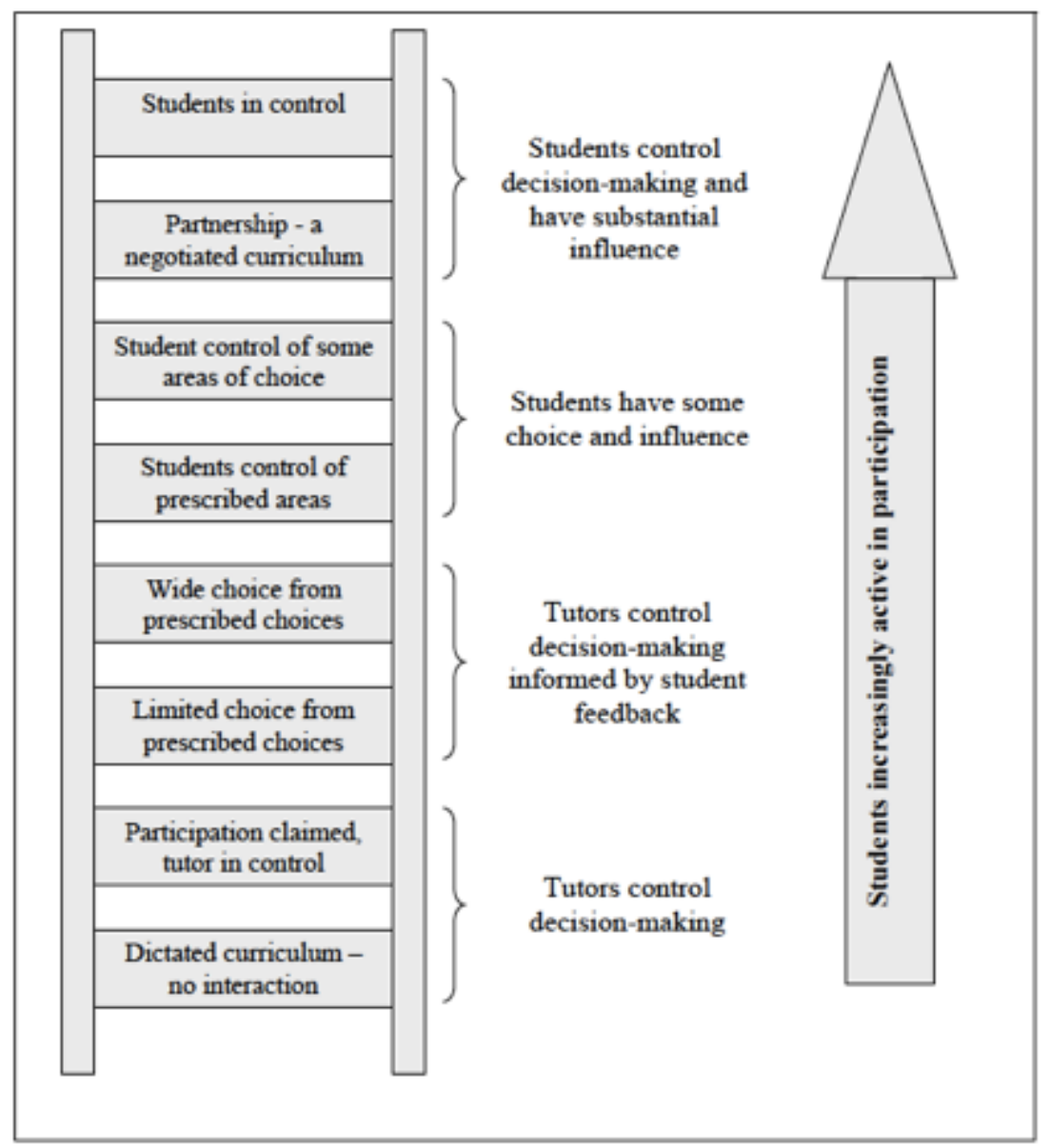

*From Bovill and Bulley (2011).

\section{Partnership is dialogic experience}

Research suggests that students engaged as partners in curriculum design and development start viewing education differently and take on a more active role, becoming more invested in learning as they develop a greater sense of responsibility and trust (CookSather \& Alter, 2011; Manor, Block-Schulman, Flannery, \& Felten, 2010; Werder, Thibou, \& Kaufer, 2012). The Students-as-Partners model offers an opportunity for faculty and students to work together towards a single, shared goal (Cook-Sather et al., 2014). Matthews (2016) states that in this model the partnership is considered a process of "engaging with rather than doing to or doing for students" (p. 2). Werder et al. (2012) argue that partnerships, when done correctly, help students come to understand learning as a dialogic experience that is divergent and driven by difference. The model questions the hierarchical dynamics inherent in the contemporary education system that make it difficult for students to be active learners. Both faculty and students come to value the equality that comes with partnership, and the model enables all participants to have a voice in the decision-making process. Hence, engaging a Students-as-Partners model was at the core of this service-learning-oriented course. 
To successfully implement SaP pedagogy in an international context and for global learning, the participants in the Guatemala practicum adopted the principles of collaborative learning, feminist pedagogy, and constructivism. Rather than lecturing, the instructor assumed a role of facilitator of the learning process, frequently modeling the behavior of a learner and encouraging students to position themselves in a similar space: that of engaged and active learners involved in the process of self-directed and self-paced learning. Students shared leadership with faculty in course development, in conducting classes, completing research assignments, and designing, implementing, and evaluating special projects, done individually or in small groups.

\section{Partnership as a way of developing participants' sense of trust, belonging and community}

The development of all participants' sense of belonging and a sense of community was another core aspect of the course experience. Once again, relying on previous research, we know that pedagogical partnerships enable students to develop an increased sense of community (Healey et al., 2014) and a greater sense of belonging (Curran \& Millard, 2016). Cook-Sather (2015), who collected reflections and analyses of faculty and student experiences and voices participating in the SaLT program at Bryn Mawr, argues that collaboration and partnership inspire more openness, deeper connection, and more empathy among students and faculty, and that partnerships foster underrepresented students' affective experiences. It increases students' engagement in other courses they are taking and contribute to their sense of evolution as active agents in their own and others' development (Cook-Sather, 2015). Collaboration among all of those involved in service-learning courses abroad benefits from the use of the SaP approach, particularly one that is developed in the context of community-based international programs (Heine, 2018). Through engaging among themselves and with the instructor, students were able to perform and develop a better awareness of their own identities, shaping them through their interactions with others (Fiksdal, 2014). Collaborative learning involved students in group projects wherein the preparation and delivery were decided jointly by group members with assistance from the instructor. By using this approach, students took responsibility for their own learning individually and as a team, made choices about assignments, self-monitored their progress, constantly reflected on and evaluated the process of teaching and learning, and provided constructive feedback throughout the experience. For example, based on educational and professional interests as well as their abilities and language skills, students selected their placement or the agency they were going to work with from a selected group of pre-identified community partners.

Prior to arriving to Guatemala, a "buddy" (friendship) system was established among students during the pre-departure course to construct shared experiences and help each other with agency tasks and assignments, as well as to keep each other safe. In addition to working in the same agency, students were placed together in guest homes. All students were provided with a local phone so that they were reachable at all times by their instructors, student leader, and peers and to use in the eventuality of a personal or group emergency.

Partnership-based teaching and learning approaches used in the development of the Guatemala practicum course sought to promote an atmosphere of trust and community in 
which both the instructor and students were encouraged to do the same. Students actively participated in class and worked together as a team rather than as competitors. Small group discussions, discussion forums, and other forms of interaction and web-based tools were utilized in teaching. Introspective techniques in learning were also used. One student wrote in her course assessment during the 2018 winter term:

Knowledge and skills that have been operationalized or enhanced in my assignments and service work through this practicum experience are effective communication, flexibility, and teamwork. Throughout the practicum experience, effective communication was an important skill to have because of the language and cultural barrier that existed between the workers and volunteers. Effective communication was needed so that we as volunteers could be effective workers. Flexibility was another skill that I applied during my practicum experience because there were many times where events did not go initially as planned and I was required to adjust my attitude and expectations in order to accommodate these changes. Teamwork was probably the biggest skill that I used during my practicum experience. Almost everything that I did throughout the practicum required group work and always involved a group of people. I had to learn to work together with others in order to meet the goals we set out to achieve.

Using ethical values as core principles, the instruction was oriented toward creating a learning environment free from prejudice and discrimination based on sex, race, ethnicity, class, age, religion, sexual orientation, and physical or mental abilities. Faculty observations regarding the diversity of student identities are valuable regarding issues of identity and ethics. For the most part, students at Elon have a shared North American identity when working abroad; the Guatemala Program involved students with a wide range of identities and with multiple identities. Students who identified as White expressed being changed by the experience of becoming a minority group in Guatemala. Students of Latino heritage had the opposite experience; they were part of the majority group in Guatemala when at Elon they are part of the minority group. Students who identified as male (another minority group in the professional field) reported becoming allies by assuming protective roles in a male-dominated (Machista) culture where violence against women prevailed, from street sexual harassment to femicide (killing of women because of their gender). Faculty, joined by student leaders, strived to create an affirming environment for students who identified as lesbian or queer, given the heteronormative culture often experienced in Elon study-abroad groups and within the mentioned Machista culture. A student leader who identified as Black had an affirming experience when visiting the Atlantic coast community of Livingston, which has a majority AfroLatino population. The students who identified as Jewish had minority group experiences in a country with a largely Catholic population. All participants had a minority group experience by engaging with Highland communities from diverse ethnic groups in a country with a majority indigenous population.

Participants found the cross-cultural, cross-linguistic components of the Guatemala practicum challenging and rewarding. In Guatemala, a country with mostly indigenous people, 
students who had not been exposed to diverse populations prior to this course had both similar and different experiences than those who were fluent in Spanish and/or claimed being Hispanic or of Latin American heritage. One student wrote in her course assessment during the 2018 winter term:

Being able to communicate with the kids in the indigenous community in the highlands, where we did not speak the same language, but still being able to find a way to play a game together, and laugh together, was one of my most treasured learning experiences. At Obras [Sociales del Santo del Hermano Pedro, a hospital for low-income residents of Antigua Guatemala providing residential services to people with severe physical and intellectual disabilities], I learned even more [about] the ease of human connection through working with children who not only did not speak my language, but also did not speak at all. I was still able to help them and make them laugh. And that really taught me the power of human services, and reassured me that this is what I wanted to do with my life.

While performing their evolving identities in interaction with others, students were able to gain greater cultural competence that is essential for providing human services in international settings. The use of the SaP approach promoted building a more trusting, egalitarian, reflective, and collaborative teaching and learning experience and helped all the participants-the students, instructor, and community partners-develop respect for and understanding of the differences and the unique attributes of all participants in this international practical experience.

Critical thinking, critical reading, and critical writing were also encouraged upon recognition of existing paradoxes in every social topic introduced as part of the curriculum, as well as every direct experience that students had during the practicum. One student, who selfidentified as White and who had prior experience of serving children with cerebral palsy, wrote in her course assessment during the 2018 winter term:

In most human services classes, you learn about ideas and they are somewhat implicit, but in this case, the ideas were very explicit. For example, after learning about the three dimensions of Multiple Identities, I really started to think about the kids [with cerebral palsy] I was working with. The day after learning about them, when I went into the hospital and was playing with the kids, I found myself actually wondering "what is this kid's history? How could their history that I don't know change the way I understand them?" This also occurred after learning about the strength-based model. Because it was so easy to apply them at Obras, I now have good practice and can apply the frameworks and the type of thinking that they induce in my future [professional] placements.

Another student, who self-identified as Latina and was from the same course and the same agency placement, confirmed the interaction of identity in the context of collaborative learning schemes: 
Working at Obras Sociales with my group of five other people was the highlight of my practicum experience. It made working in a difficult environment a lot easier and provided us with a way to process and discuss our experiences. It made group work a lot easier and also provided us with a sense of comradery that made the practicum experience a lot more fun.

Using the ladder of student participation in curriculum design (Bovill \& Bulley, 2011) introduced earlier (see Figure 2), the SaP experience in the context of the Guatemala practicum can be understood in the upper levels of student participation in course development. For instance, community partners in Guatemala pre-identified the agencies that students ultimately selected for their practicum experience. Students assumed control over their learning process through the development of learning plans, which guided their daily activities over the course of 3 weeks. The two student-partner researchers engaged in the Guatemala practicum study explained that they achieved higher levels of participation when students were invited to codesign their specific research projects together with the faculty mentor prior to arrival to Guatemala. Below is an explanation of these two forms of student participation in curriculum development and in research design.

Faculty and students working collaboratively on the design, implementation, and evaluation of specific practicum activities is a form of SaP approach. Data from the Guatemala practicum suggest that although students acquired a basic knowledge of the host country in the United States and later when in Guatemala, it was from the self-directed and collaborative learning-when preparing the background paper and having direct practice through the agency placements - that they gained a deeper understanding of the host country and developed intercultural competency. They all gained practical experience in working with diverse populations, which they selected and studied prior to arrival. The served population included children and adults with disabilities, women who had suffered domestic partner violence, and undernourished children from low-income families. Some students gained intercultural sensitivity by identifying where they felt situated within the ethnocentric and ethnorelative continuum while others became aware of the specific abilities and skills acquired. Yet, others acknowledged that the practicum experience helped them develop a better sense of their "helping attractiveness" (as defined in Harper \& Lantz, 1996), an essential attribute for service providers working across cultures. Consequently, the use of a SaP approach during the practicum not only deepened student engagement, enhanced learning, and developed better self-awareness, but also helped develop students' cultural and intercultural competence.

Gaining cultural and intercultural competence was conducive to higher SaP outcomes. The process was reciprocal. For example, faculty-student partnership was also experienced in the immersion component of the Guatemala practicum. Language is a means for learning about cultures and the data suggest that students determined how much Spanish they would learn based on the relationships they had established with their assigned Guatemalan teacher partners and the population they served through their respective practicum experiences. In fact, most students reported learning practical language skills through the one-teacher-onestudent model of daily classes, using experiential learning methods. In their agency placements, 
students were able to use their prior language skills and that of their peers to communicate with the populations they served.

The Guatemalan community partners appreciated the students' work and support. They saw students as allies in serving vulnerable people and special populations in Guatemala. For instance, staff members from Obras expressed to the faculty that they preferred to welcome and supervise Elon students as opposed to other student volunteers, because students from this course were involved in a professional practice learning to work the "Guatemala way" of delivering services and to serve highly vulnerable populations.

These conclusions derived from the Guatemala practicum research suggest the need for the adoption of a global learning model for practicum instruction, as depicted in Figure 2, which in turn enables SaP approaches. In this interactive model, the four stages of awareness, experience, perspective, and competence create feedback loops with each other. Awareness starts in pre-departure and expands through the practicum experience. The direct experience students have is acquired in the work they develop with the agency partners in their practicum placements and during any other community field work. Their perspective changes as the practicum experience evolves. Their competence increases as they are able to assess the accomplishment of their learning outcomes, set prior to conducting the practicum experience.

\section{Figure 3. Global learning model for practicum instruction}

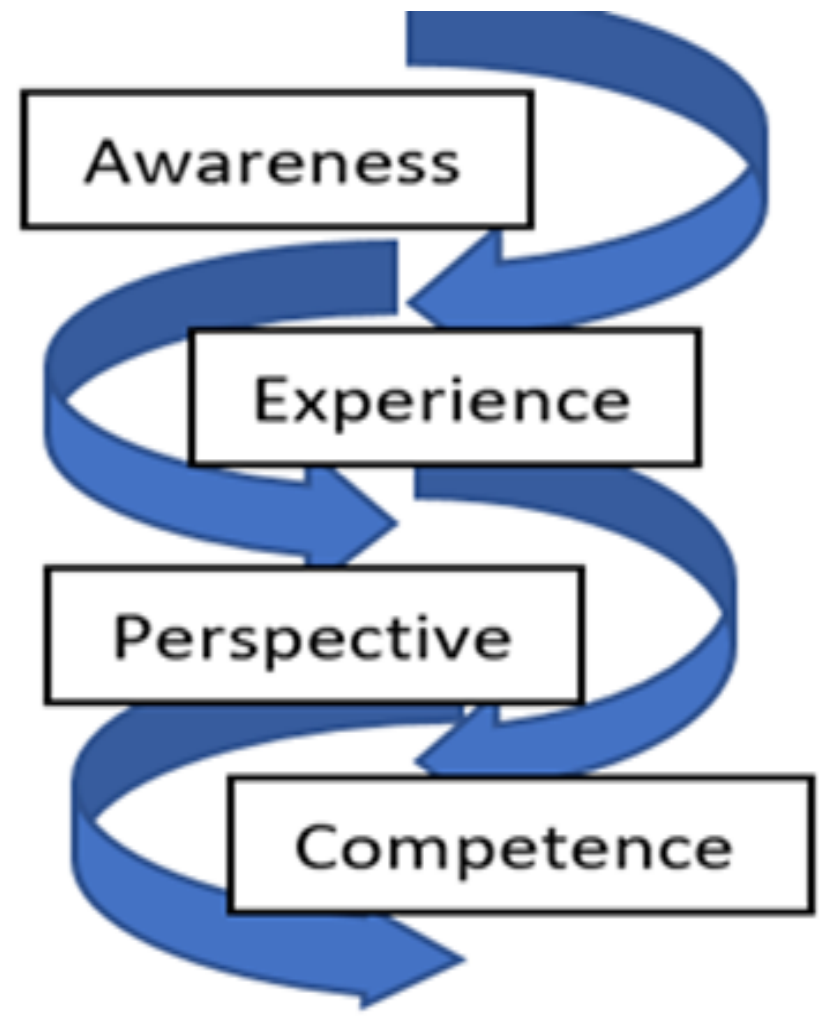




\section{Student partnership in research: Emerging design of a student-directed project in Guatemala}

As explained earlier, the Guatemala research project adopted the naturalistic inquiry approach, which includes the implementation of an emerging design. This allowed for student engagement in the design of specific assessments through student-directed research projects. Below is an example of the student-researcher perspective on the complexity of designing a research project and analyzing data collected from the self-reports of student-participants:

This past summer I was responsible for analyzing data previously collected from Study Abroad Guatemala practicums. Study Abroad trips and practicums are often popular with undergraduate students and professors, and institutions hope their students get the most out of their experiences. The problem is that measuring the satisfaction of students and measuring how much they learned from another culture and experience is hard to categorize and organize. For the Guatemala Study Abroad Practicums we wanted to understand how students felt about their different agencies and their experiences abroad as well as what cultural competence they may have gained. (Report from Program/Research Assistant 2, Final Report, September 4, 2017)

This particular student-researcher designed an analytical approach that allowed us to use the data collected in the Student Evaluation of Practicum Field Experience, which uses a Likert-type scale from Strongly agree to Strongly disagree, with an option of Unsure, to assess the student participants' perceptions of working with each agency. The usefulness of adopting an emerging design can be appreciated in this reflection of the descriptive analysis of the data collected over the course of 5 years:

Labeled on the Excel Sheet x-axis was the Question Numbers from the Student Evaluation of Practicum Field Experience and on the y-axis was labeled the responses of the participants for each question. Once the data for an agency were entered they could be analyzed by each individual question and the mean response from all participants could be generated. ... . Once the mean for each individual question within an agency was acquired, another Excel Sheet that combined all the agencies was created. ... Having the data all combined into one Excel Spreadsheet was extremely helpful when analyzing the data. Once the data were organized into a table that could be read, it was necessary to start to think about the different patterns that appeared through the data. While there were numerous ways to analyze the data, the data were analyzed by question rather than by agency. (Report from Program/Research Assistant 2, Final Report, September 4, 2017)

Through emerging design, the student-researcher was able to make important decisions about how to analyze the data to address the proposed research questions of this research project. Reporting on each individual question and agency where students completed their practicum is beyond the scope of this article, but the relevance of these questions to one or more areas of the aforementioned global learning model for practicum instruction is critically important. 


\section{CONCLUSION}

The model described in this article is an example of constant learning through practicum instruction, which does not have a beginning or end, but a process of learning. This process enabled students to become more culturally competent, more actively engaged as learners and teachers, and more self-aware and conscientious global citizens. The SaP approach is crucial for this model as it encourages student responsibility in their own learning and, as a consequence, develops a better sense of responsibility for learning and teaching in students and reciprocity between student and faculty. This project brought together three components of high-impact practices in education: Students-as-Partners pedagogy, the development of students' intercultural competency through their experiences, and learning abroad and experiential or service learning. All three components helped participants develop a better sense of responsibility toward and engagement with the community and acquire greater knowledge of and respect for diverse modes of being, viewing the world, and points of reference.

The model of Students as Partners or students as co-teachers, co-researchers, and comentors is inherent in the teaching and learning philosophy used throughout this course experience. The Guatemala practicum offers an example of a successful implementation of a partnership-based pedagogy that leads to achieving better results in terms of developing students' advanced global knowledge and improving not only their service learning experiences abroad, but the relationships established between the students and community partners. We have envisioned this practicum as addressing some of the deep values reinforced by studentfaculty partnership pedagogy: that of active and engaged learning, of education as a more democratic structure and process, and of fostering spaces in which all participants experience an enhanced sense of belonging and community-building. Our colleagues at the university shared these values, which are closely aligned with our institutional goals.

Elon considers student engagement and experiential learning opportunities, together with the development of students' global and intercultural knowledge, to be some of the most valuable high-impact practices, and the university strives to build a campus with a strong sense of community and civic and social responsibility. The outcomes of the experience described in this article fit well within our university's mission and goals. The research associated with the Guatemala practicum suggests that the use of SaP pedagogy strengthened the Human Service Studies curriculum development, and as a consequence, allowed us to successfully address our university's commitment to educate "engaged minds, inspired leaders and global citizens" (Elon University, n.d.).

SaP pedagogy combined with the inter-institutional and cross-disciplinary context of the course offered an opportunity for addressing the need to build global competencies among students. By using the practicum as a way of fulfilling their professional practice, students were engaged in service-learning activities while achieving greater commitment to the process of teaching, learning, and research. The SaP pedagogy promoted a better sense of community among students, faculty, and community partners. We hope that further research will not only capture the outcomes of the experience of international human-service delivery through partnerships with students and local community organizations, but will also offer diverse examples of SaP pedagogy used in inter-institutional and cross-disciplinary contexts. 


\section{NOTES ON CONTRIBUTORS}

Ketevan Kupatadze is a senior lecturer of Spanish at Elon University. Between the years 2017-19 she has collaborated with the Center for Engaged Learning at Elon as a scholar whose project focused on student-faculty partnerships.

Carmen Monico is an Associate Professor in the Joint Master and PhD Social Work Programs of the North Carolina Agricultural and Technical State University (A\&T) and the University of North Carolina Greensboro (UNCG). Her transnational scholarship includes global migration, human trafficking, global engagement, and community-based research locally and internationally.

\section{REFERENCES}

Bennett, M. J. (1993). Towards ethnorelativism: A development model of intercultural sensitivity. In R. M. Paige (Ed.), Education for the intercultural experience (pp. 21-72). Yarmouth, ME: Intercultural Press.

Borrell-Carrio, F., Suchman, A. L., \& Epstein, R. M. (2004). The biopsychosocial model 25 years later: Principles, practice, and scientific inquiry. Annals of Family Medicine, 2(6). https://doi.org/10.1370/afm.245

Bovill, C. (2017). A framework to explore roles within student-staff partnerships in higher education: Which students are partners, when, and in what ways? International Journal for Students as Partners, 1(1). https://doi.org/10.15173/ijsap.v1i1.3062

Bovill, C., \& Bulley, C. J. (2011). A model of active student participation in curriculum design: Exploring desirability and possibility. In C. Rust (Ed.), Improving student learning (ISL) 18: Global theories and local practices: Institutional, disciplinary and cultural variations (pp. 176-188). Series: Improving Student Learning (18). Oxford, UK: Oxford Brookes University, Oxford Centre for Staff and Learning Development.

Cook-Sather, A. (2015). Dialogue across differences of position, perspective, and identity: Reflective practice in/on a student-faculty pedagogical partnership program. Teachers College Record, 117(2). Retrieved from https://repository.brynmawr.edu/edu pubs/32/

Cook-Sather, A., \& Abbot, S. (2016). Translating partnerships: How faculty-student collaboration in explorations of teaching and learning can transform perceptions, terms, and selves. Teaching \& Learning Inquiry, 4(2), 1-14. Retrieved from https://doi.org/10.20343/teachlearninqu.4.2.5

Cook-Sather, A., \& Alter, Z. (2011). What is and what can be: How a liminal position can change learning and teaching in higher education. Anthropology \& Education Quarterly, 42(1), 37-53. https://doi.org/10.1111/j.1548-1492.2010.01109.x

Cook-Sather, A., Bovill, C., \& Felten, P. (2014). Engaging students as partners in learning and teaching. San Francisco, CA: Jossey-Bass.

Cox, D. R., \& Pawar, M. S. (2013). The integrated-perspectives approach to international social work. In D. R. Cox \& M. S. Pawar (Eds.), International social work: Issues, strategies, and programs (2nd. ed., pp. 67-104). New York, NY: Sage. 
Curran, R., \& Millard, L. (2016). A partnership approach to developing student capacity to engage and staff capacity to be engaging: Opportunities for academic developers. International Journal for Academic Development, 21(1), 67-78. https://doi.org/10.1080/1360144X.2015.1120212

Elon University (n.d.). The Elon commitment: Engaged minds. Inspired leaders. Global citizens. Retrieved from https://www.elon.edu/u/administration/president/strategic-plan-2020/

Fiksdal, S. (2014). A guide to teaching effective seminars: Conversation, identity, and power. New York, NY: Routledge.

Freire, P. (1968). Pedagogy of the oppressed. New York, NY: Seabury.

Guba, E. G., \& Lincoln, Y. S. (1989). Fourth generation evaluation. Newbury Park, CA: Sage.

Harper, K. V., \& Lantz, J. (1996). Cross-cultural practice - Social work with diverse populations. Chicago, IL: Lyceum Books.

Healey, M., Flint, A., \& Harrington, K. (2014). Engagement through partnership: Students as partners in learning and teaching in higher education. York, UK: Higher Education Academy. Retrieved from https://www.heacademy.ac.uk/engagement-throughpartnership-students-partners-learning-and-teaching-higher-education

Healey, M., Flint, A., \& Harrington, K. (2016). Students as partners: Reflections on a conceptual model. Teaching \& Learning Inquiry: The ISSOTL Journal, 4(2), 1-13. https://doi.org/10.20343/teachlearninqu.4.2.3

Heine, C. (2018). Students as partners in a service-learning program: Speech pathology students in Cambodia. Partnerships: A Journal of Service-Learning and Civic Engagement, 18(9), 1, 18-30. Retrieved from http://libjournal.uncg.edu/prt/article/view/1482

Kenyon, P. (1999). Ethical decision-making in human services. In What would you do?: An ethical case workbook for human service professionals (1st ed., pp. 3-20). Pacific Grove, CA: Brooks Cole.

Kiser, P. (2000). Getting the most from your human service internship: Learning from experience. Pacific Grove, CA: Brooks/Cole.

Kupatadze, K. (2019). Opportunities presented by the forced occupation of liminal space. International Journal for Students as Partners, 3(1), 22-33. https://doi.org/10.15173/ijsap.v3i1.3744

Lincoln, Y. S., \& Guba, E. G. (1985). Naturalistic inquiry. London, England: Sage.

Manor, C., Block-Schulman, S., Flannery, K., \& Felten, P. (2010). Foundations of student-faculty partnerships in the scholarship of teaching and learning. In C. Werder \& M. M. Otis (Eds.), Engaging students voices in the study of teaching and learning (pp. 3-15). Sterling, VA: Stylus.

Matthews, K. E. (2016). Students as partners as the future of student engagement. Student Engagement in Higher Education Journal, 1(1), 1-5. Retrieved from https://journals.gre.ac.uk/index.php/raise

Mercer-Mapstone, Dvorakova, S. L., Matthews, K. E., Abbot, S., Cheng, B., Felten, P., Knorr, K., Marquis, E., Shammas, R., \& Swaim, K. (2017). A systematic literature review of students as partners in higher education. International Journal for Students as Partners, 1(1), 123. https://doi.org/10.15173/ijsap.v1i1.3119 
Robinson-Wood, T. L. (2013). Multiple identities defined. The convergence of race, ethnicity, and gender: Multiple identities in counseling (4th ed., pp. 1-19). Boston, MA: Pearson.

Rodwell, M. K. (1998). Social work constructivist research. New York, NY: Garlands.

Timberlake, E. M., Zajicek-Farber, M., \& Sabatino, C. A. (2008). The generalist perspective. In Generalist social work practice: A strengths-based problem-solving approach (5th ed., pp. 15-31). Boston, MA: Allyn \& Bacon.

Werder, C., Thibou, S., \& Kaufer, B. (2012). Students as co-inquirers: A requisite threshold concept in educational development. Journal of Faculty Development, 26(3), 34-38. 